\title{
A Study of the Closed-Loop Supply Chain Coordination on Waste Glass Bottles Recycling
}

\author{
Wenxue Ran, Fan Chen, Qianni Wu, and Sen Liu \\ School of Logistics, Yunnan University of Finance and Economics, Kunming 650221, China \\ Correspondence should be addressed to Sen Liu; liusencool@gmail.com
}

Received 2 February 2016; Accepted 17 April 2016

Academic Editor: Rosa G. González-Ramírez

Copyright ( 2016 Wenxue Ran et al. This is an open access article distributed under the Creative Commons Attribution License, which permits unrestricted use, distribution, and reproduction in any medium, provided the original work is properly cited.

\begin{abstract}
The recycling of waste products can sharply save manufacturing cost and improve the economic efficiency and corporate-reputation. It also has a great effect on the environment and resources protection. In the management of the closed-loop supply chain, the recycling of waste products and decision-making on pricing often directly affect the supply and demand of products and the operation efficiency of supply chain. Therefore, first we take waste glass bottles as an example and establish a mathematical model to solve the profit of manufacturers and retailers solely. Then, we analyzed whole supply chain profit under a dual-channel recycling condition which is directly recycled by consumers or by retailers. Finally, we concluded that no matter what product's price, quality, profit, or operational efficiency of supply chain is, the overall recycling is better than the single node recycling model. Based on the analysis, we developed a new model to coordinate the profit of manufacturers and retailers in the supply chain with revenue-sharing contract. A numerical study shows that this approach is applicable and effective.
\end{abstract}

\section{Introduction}

With the development of science and technology and consciousness growth of limited resource, the reuse of resources has been widely concerned. The increase in population and consumption has brought more household waste. Waste glass bottles are one of types of garbage which are most difficult to handle. According to statistics, waste glass product in a Chinese city is more than 7 million tons each year, accounting for $3 \%-5 \%$ of the total municipal waste. The world average of waste glass recycling rate is close to $50 \%$ now. Taiwan has reached $84 \%$ and Germany has already up to $97 \%$, but only $13 \%$ in China. Shenzhen, for example, produces a large number of waste glass bottles and building glass rubbish every day. Only consider the consumption of Jinwei, Qingdao, and other major beer brands; there are 500 million bottles per year. Shenzhen consumes more than one billion bottles one year. In other words, demand for glass in Shenzhen is nearly 500,000 tons a year. However, the classification system of garbage collection in China is not perfect now; it cannot be unified to collect the broken glass or glass products. Household waste glass bottles can be handled together with other types of garbage; part of them will be melted in high-temperature, to make the building materials with coal cinder; the other part will be transported to the landfill. After being crushed down in the garbage disposal plant, waste glass bottle has been thrown to landfill, causing solid pollution. At the same time, some garbage bottle containing special ingredients will lead to secondary pollution on soil and atmosphere. Even if some enterprises adopt the recovery mechanisms but also make residents waste a lot of recyclable waste glass just because of the system is not perfect. Study on how to reduce or enhance waste recycle will make a significant contribution to improve the social effect and economic effect.

Recycling logistics is developed in the rising awareness of environment protection, gradual exhaustion of resources, and increasing competition in the market. It broke the bottleneck in the development of forward logistics. The process of recycling logistics is often accompanied with capital flow, information flow, and business flow. It will save a lot of social resources, reduce the operating costs, and improve customer satisfaction.

On the issue of recycling, Jun [1] thought that creating business value in recycling and remanufacturing is the key to sustainable development. Through the perspective of commercial value, he explained how to get through the integration 
of subprocesses to obtain the recovery product value. Pan et al. [2] also believed that the reverse logistics business is becoming a new way to achieve sustainable development in enterprise and analyzed reverse logistics costs and benefits to explore the cost-benefit optimization model of reverse logistics. Govindan et al. [3] have made a review of recently published papers and proposed that utilizing new approaches and applying greener, sustainable, and environmental objectives can be the future directions in reverse logistic. Under both joint and individual productions with different cost structures, Lu et al. [4] proposed that different firms can cooperate in their recycling and pricing decisions using cooperative game theory to maximize total profit. Zerhouni et al. [5] proposed two reverse logistics systems: one with returns independent of demand and the other with returns dependent on demand. They provide a numerical method to compute the optimal base-stock level and found that ignoring the dependency between demands and returns can increase the cost. But starting from the whole supply chain and how to choose the recyclers, Giovanni and Zaccour [6] studied the conditions of recycle by manufacturers and outsourced recovery operations to a third-party retailer in the closedloop supply chain through the different established models. J. Wei and H. Wei [7] hold that specialized superiority in third-party logistics service can reduce the leading corporate capital investment, diversify management risk, and improve service level; it is an ideal choice in reverse logistics process. Taking electronic product as an example, Hong and Yeh [8] studied a closed-loop supply chain model which recycles by one retailer and analyzed the impact of third-party nonprofit recovery organization for closed-loop supply chain system. Zhou [9] analyzed the coordination of supply chain and the distribution of interest from different perspective when third-party logistics entered. All the above papers have made the analysis in the operating mechanism when third-party logistics entered. Chuang et al. [10] focused on the collection cost structures of the manufacturer, retailer, and third-party firm and got the following: if they are similar, retailer is optimal when the collection cost exhibits economies of scale, whereas manufacturer is optimal when the collection cost exhibits diseconomies of scale. But if they are different, the best recycler is the one who has a lower marginal collection cost. Considering the impact of environmental costs and social benefits, from Ramos et al. [11], the problem can be modeled as a multiobjective, multidepot periodic vehicle routing problem with interdepot routes. Wang [12] discussed the mode of recycling waste products by dualchannel in closed-loop supply chain management under the measures of government, and she believed that collaborative decision-making model under government interference can be achieved by effective coordination mechanisms combine with effective government incentives. When retailers and third parties are competed with each other and recycle at the same time, Huang et al. [13] studied the conditions by which manufacturers choose to build dual-channel. The cost is always a difficult problem in reverse logistics. Under the deterministic demand and the stochastic demand cases, $\mathrm{He}$ [14] studied the optimal production decision and the optimal acquisition pricing decision from the centralized recycle channel and the decentralized recycle channel. He showed that under decentralized recycle channel structure, the optimal acquisition price is always lower than the optimal acquisition price under centralized recycle channel structure. For dual-channel sales and dual-channel recovery in loop supply chain, Hao [15] established a tripartite game model which included manufacturers, retailers, and third-party recycling enterprise and analyzed and verified the coordination mechanism of compensation contract and cost sharing contract for the supply chain system. Ma [16] also researched on the strategy of optimal recycling channels for manufacturers from design coordination mechanism in the closed-loop supply chain channel selection, network equilibrium, and coordination of benefits under the case of multiple recycling channels. In order to maximize the profit of the closedloop supply chain, Wei and Zhao [17] studied the optimal retail price and wholesale price of the closed-loop supply chain in retailers competition under game theory and fuzzy theory. Liang et al. [18] used the future pricing model to study the recycling products pricing problem when sales follow the geometric Brownian motion in centralized decision. Yi and Liang [19] contrastively analysed three different mixed recycling models and got the conclusion that manufacturers and retailers recycling jointly is the optimal recovery mode. And they stated the system performance and pricing strategies under different recycling channels and different recovery efficiency in closed-loop supply chain. Since a different sales price exist in new products and remanufactured products, Zhang and Yang [20] researched on the recycling and sales pricing strategy in closed-loop supply chain system.

But, for the glass-packaged product, the price of a new one and a remanufactured one are the same; the recycling cost is the main factor that affects the profit. So, in this paper, we consider to establish a two-channel recycling model to discuss the function of recovery rate in the whole supply chain and how will manufacturers and sellers play the game so that the price can impact the profit of supply chain. This research can help the corporation to combine their own conditions to plan recycling channels or make recycling decisions.

\section{The Proposed Method}

2.1. Problem Statement. First, after the use of glass packaging products, waste glass bottles can be exchanged for original glass packaging products (or cash) at point-of-sale, partially recovered by the recyclers to waste station. In this process, transportation and storage costs will be generated by the storage of bottles. Then, at point-of-sale, the company which produces the glass packing production needs to send bottles back to their factory from every point-of-sale regularly. Workers in waste station also need to ship their recovered bottles to the company. The logistics costs and losses occurred in the logistics process offered by the recycling individual or enterprise. They should pay attention to explosion-proof bottles. During the transportation process, plastic trays can be available. According to the distance and traffic conditions of collection points, logistics and transport costs will be different. After bottles being shipped back to company, they will be tested for whether being qualified. Qualified one 


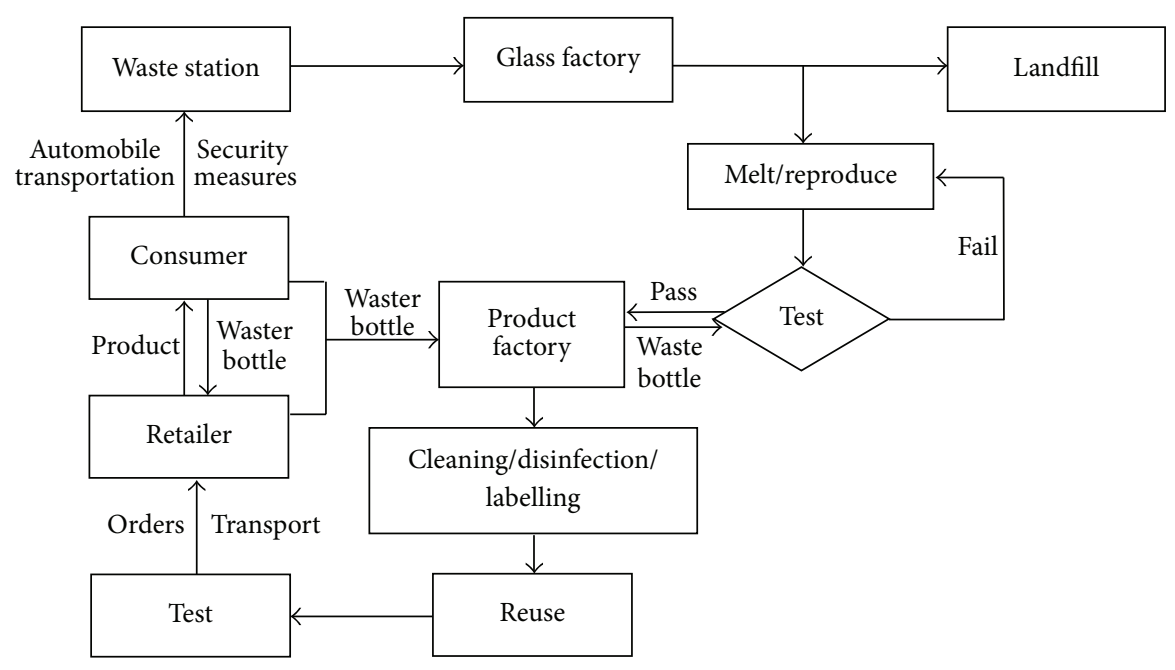

FIGURE 1: Recovery process of waste glass bottles in scale recycling.

can be continued to refilling after cleaning, disinfection, and other steps in production line and, then, enter the market again. However, unqualified one will be shipped to the glass factory, melt or embed it.

This paper is based on Stackelberg game and the sharing contract of revenue and expense to achieve the allocation and maximization of supply chain profit.

Figure 1 showed the general handing process of waste glass bottles.

2.2. Notation and Definitions. This paper mainly on supply chain system consists of manufacturers, retailers, and consumers. Manufacturers recycle waste glass bottles from consumers directly or by sellers for the production, such as beer bottles and yogurt bottles. In production, recycled and reused waste glass bottles do not affect the sales price.

The practical significance of the relevant symbols in this paper is as follows:

\section{$I$ : profit of the entire supply chain;}

$I_{M}$ : glass packaging product manufacturer's profit;

$I_{R}$ : glass packaging product retailer's profit;

$W$ : the wholesale price of glass packaging product manufacturer (unit/piece);

$P$ : the sales price of glass packaging product retailer (unit/piece);

$C_{m}$ : unit cost of new glass-packed product (unit/piece);

$C_{r}$ : unit cost of reproduced glass-packed product (unit/piece);

$H_{1}$ : manufacturer's unit cost of waste glass bottles recycled from consumer (unit/piece);

$\mathrm{H}_{2}$ : retailer's unit cost of waste glass bottles recycled from consumer (unit/piece);

$\mathrm{H}_{3}$ : manufacturer's unit cost of waste glass bottles recycled from retailer (unit/piece);

$\gamma$ : recovery of waster glass bottles;
$X_{1}$ : the proportion of waste glass bottles recycled by manufacturer in overall recovery;

$X_{2}$ : the proportion of waste glass bottles recycled by retailer in overall recovery; $\left(X_{1}+X_{2}=1\right)$;

$\Delta$ : cost saved by each unit; $\Delta=C_{m}-C_{r}$.

\section{Correlative Hypothesis}

(1) The market of glass-packed product is very mature. There are many available waste bottles for recycling currently and the market demand is very great.

(2) In the model, manufacturers and retailers of glasspacked product can make decisions independently and pursue their maximum profit. Manufacturers play a leading role.

(3) The feature of remanufactured product can satisfy consumers the same as the new product. They provide the same value.

(4) The production cost of glass-packed remanufactured product should be less than production cost of new product. This is the driving force for recycling and remanufacturing.

(5) Manufacturers and retailers of glass-packed product share their information that is a support condition for normal running in supply chain.

(6) Recovery refers to the ratio of the number of recycling waste glass bottles from consumers to the number of sales. That is, the ratio of remanufacturing product to the total output; $0<\gamma<1$.

(7) $\Delta>H_{1}>2 H_{2}, H_{1}>H_{3}>H_{2}$.

(8) The market demand is a function of price $(a / b$ are positive constant):

$$
M(P)=a-b p .
$$


(9) Recycling cost of retailer is

$$
C_{1}=K \gamma^{2}+H_{2} \gamma X_{2}(a-b p) \text {. }
$$

(10) Cost of manufacturer is

$$
C_{2}=K \gamma^{2}+H_{2} \gamma X_{2}(a-b p) .
$$

2.3. Analysis of Profit. Sold products price times its quantity then minus the production cost and recycling cost can get the manufacturer's profit. Revenues from sold products and recycle waste glass bottles to manufacturer minus recycling cost and purchase cost can get the retailer's profit. The profit of whole supply chain is manufacturer's profit plus retailer's profit. Manufacturer and retailer's profit is the following:

(1) Profit of glass-packed product manufacturer:

$$
\begin{aligned}
I_{M}= & W(a-b p)-C_{m}(a-b p) \\
& +\left(C_{m}-C_{m}\right) \gamma(a-b p)-K \gamma^{2} \\
& -H_{1} X_{1} \gamma(a-b p)-H_{3} X_{2} \gamma(a-b p) \\
= & \left(W+\Delta \gamma-C_{m}-H_{1} X_{1}-H_{3} X_{2}\right)(a-b p) \\
& -K \gamma^{2} .
\end{aligned}
$$

(2) Profit of glass-packed product retailer:

$$
\begin{aligned}
I_{R}= & P(a-b p)-W(a-b p)-K \gamma^{2} \\
& +\left(H_{3}-H_{2}\right) X_{2} \gamma(a-b p)-H_{2} X_{2} \gamma(a-b p) \\
= & {\left[P+\left(H_{3}-H_{2}\right) X_{2} \gamma\right](a-b p)-K \gamma^{2} . }
\end{aligned}
$$

(3) Profit of whole supply chain:

$$
\begin{aligned}
I= & (a-b p)-C_{m}(a-b p)+\left(C_{m}-C_{m}\right) \gamma(a-b p) \\
& -K \gamma^{2}-H_{1} X_{1} \gamma(a-b p)-K \gamma^{2} \\
& -2 H_{2} X_{2} \gamma(a-b p) \\
= & \left(P+\gamma \Delta-C_{m}+H_{1} X_{1} \gamma-2 H_{2} X_{2} \gamma\right)(a-b p) \\
& -2 K \gamma^{2} .
\end{aligned}
$$

(1) Independent Supply Chain Model. In this case, glasspackaged product manufacturer and retailer are independent individuals with Stackelberg game between them. And, in this model, glass-packed product manufacturer occupies a leading position. Retailers based their decisions on manufacturer's decisions. We can solve the optimum decision variables of manufacturer according to the backward induction, substituted in corresponding profit function, and get the optimum profit of manufacturer and retailer.
(2):

First, we take its partial with respect to $P$ and $\gamma$ in (1) and

$$
\begin{aligned}
& \frac{\partial I_{m}}{\partial p}=0 \\
& \frac{\partial I_{m}}{\partial \gamma}=0 \\
& \frac{\partial I_{R}}{\partial p}=0 \\
& \frac{\partial I_{R}}{\partial \gamma}=0
\end{aligned}
$$

Then we can get the following relationship:

$$
\begin{aligned}
\frac{\partial I_{M}}{\partial P}= & b C_{m}+\gamma b H_{1} X_{1}+\gamma b H_{3} X_{2}-W b-\Delta \gamma b \\
\frac{\partial I_{M}}{\partial P}= & \Delta(a-b p)-2 K \gamma-\left(H_{1} X_{1}+H_{3} X_{2}\right)(a-b p) \\
\frac{\partial I_{R}}{\partial P}= & a-b p-b p+W b+b C_{m}-\left(H_{3}-H_{2}\right) X_{2} \gamma b \\
& +H_{2} X_{2} \gamma b \\
\frac{\partial I_{R}}{\partial \gamma}= & \left(H_{3}-H_{2}\right) X_{2}(a-b p)-2 K \gamma \\
& -H_{2} X_{2}(a-b p) .
\end{aligned}
$$

Above all, the optimum $P$ and $\gamma$ of glass-packed product is as follows:

$$
\begin{aligned}
P^{\circ}= & \frac{2 K\left(a+b C_{m}\right)-A a b}{4 K b-A b^{2}}, \\
\gamma^{\circ}= & \frac{X_{2}\left(H_{3}-2 H_{2}\right)\left(a-b C_{m}\right)}{4 K-A b}, \\
X_{2}= & \frac{H_{1}-\Delta}{2 H_{3}-2 H_{2}-H_{1}}, \\
A= & \left(\Delta-H_{1}\right)\left(H_{3}-2 H_{2}\right) X_{2} \\
& +\left(2 H_{2}-H_{1}\right)\left(H_{3}-2 H_{2}\right) X_{2}^{2} .
\end{aligned}
$$

We can substitute the optimum $P$ and $\gamma$ into the objective function to get the optimum profit of manufacturer and retailer and whole supply chain; they are as follows:

$$
\begin{aligned}
I_{M}^{\circ} & =\frac{\left(a-b C_{m}\right)^{2}}{4 b}+\frac{a-b C_{m}}{2 b}\left[\left(\Delta-H_{1}\right)\right. \\
& \left.-\left(H_{1}-H_{2}\right) X_{2}\right] \gamma^{\circ}-\frac{1}{4}\left[\left(\Delta-H_{1}\right)^{2}\right. \\
& \left.+\left(\Delta-H_{1}\right)\left(3 H_{1}-5 H_{2}\right) X_{2}-H_{2}\left(2 H_{2}-H_{1}\right)\right] X_{2}^{2} \\
& -K \gamma^{\circ 2},
\end{aligned}
$$




$$
\begin{aligned}
I_{R}^{\circ} & =\frac{\left(a-b C_{m}\right)^{2}}{8 b}+\frac{a-b C_{m}}{2 b}\left[\left(\Delta-H_{1}\right)\right. \\
& \left.-\left(2 H_{3}-H_{1}-2 H_{2}\right) X_{2}\right] \gamma^{\circ}-\frac{1}{4}\left[\left(\Delta-H_{1}\right)^{2}\right. \\
& +\left(\Delta-H_{1}\right)\left(3 H_{1}-2 H_{2}-2 H_{3}\right) X_{2} \\
& \left.-2\left(H_{1}-H_{3}\right)\left(2 H_{2}-H_{1}\right) X_{2}^{2}\right] \gamma^{\circ *}-K \gamma^{\circ * 2}, \\
I^{\circ} & =\frac{3\left(a-b C_{m}\right)^{2}}{8 b}+\frac{a-b C_{m}}{2 b}\left[\left(\Delta-H_{1}\right)\right. \\
& \left.-\left(H_{1}+H_{2}-H_{3}\right) X_{2}\right] \gamma^{\circ}-\frac{1}{4}\left[2\left(\Delta-H_{1}\right)^{2}\right. \\
& +\left(\Delta-H_{1}\right)\left(6 H_{1}-7 H_{2}-2 H_{3}\right) X_{2} \\
& \left.-\left(H_{2}+H_{3}-2 H_{1}\right)\left(2 H_{2}-H_{1}\right) X_{2}^{2}\right] \gamma^{\circ *}-K \gamma^{\circ * 2} .
\end{aligned}
$$

(2) Integrated Supply Chain Model. In this model, we can see the manufacturer and retailer of glass-packed product as a whole and recycle waster glass bottles from consumer. The optimum decision variables of this model are taken partially with respect to $P$ and $\gamma$ in (3); then make it equal to 0 :

$$
\begin{aligned}
\frac{\partial I}{\partial P}= & 0, \\
\frac{\partial I}{\partial \gamma}= & 0, \\
\frac{\partial I}{\partial P}= & a-b p-b p+b C_{m}-\Delta b \gamma-H_{1} X_{1} \gamma b \\
& -2 H_{2} X_{2} \gamma b,
\end{aligned}
$$

$$
\begin{aligned}
\frac{\partial I}{\partial \gamma}= & \Delta(a-b p)-4 K \gamma-H_{1} X_{1}(a-b p) \\
& -2 H_{2} X_{2}(a-b p) .
\end{aligned}
$$

The optimum price " $P$ " and recovery " $\gamma$ " of glass-packed product are as follows:

$$
\begin{aligned}
P^{*}= & \frac{4 K\left(a+b C_{m}\right)-B a b}{8 K b-B b^{2}}, \\
\gamma^{*}= & \frac{\left[\left(\Delta-H_{1}\right)+\left(H_{1}-2 H_{2}\right)\right]\left(a+b C_{m}\right)}{8 K-B b}, \\
B= & \left(\Delta-H_{1}\right)^{2}+\left(\Delta-H_{1}\right)\left(H_{1}-2 H_{2}\right) X_{2} \\
& -\left(\Delta-H_{1}\right)\left(H_{1}-2 H_{2}\right) X_{2}^{2}-\left(H_{1}-2 H_{2}\right) .
\end{aligned}
$$

To get the profit of the whole supply chain, we can substitute the optimum variables into (3):

$$
\begin{aligned}
I^{*}= & \frac{\left(a-b C_{m}\right)^{2}}{2 b} \\
& +\frac{a-b C_{m}}{2 b}\left[\left(\Delta-H_{1}\right)+\left(H_{1}-2 H_{2}\right) X_{2}\right] \gamma^{\circ} \\
& -\frac{1}{4} \gamma^{\circ 2}\left(\Delta-H_{1}\right)^{2} \\
& -\frac{1}{4} \gamma^{\circ 2} 2\left(\Delta-H_{1}\right)\left(H_{1}-2 H_{2}\right) X_{2} \\
& +\frac{1}{4} \gamma^{\circ 2}\left(2 H_{2}-H_{1}\right)^{2} X_{2}^{2}-2 K \gamma^{\circ 2}
\end{aligned}
$$

(1) Comparing the optimum price and recovery under independent supply chain model and integrated supply chain model, we can get (9)-(16):

$$
\begin{aligned}
P^{\circ}-P^{*} & =\frac{2 K\left(a+b C_{m}\right)-A a b}{4 K b-A b^{2}}-\frac{4 K\left(a+b C_{m}\right)-B a b}{8 K b-B b^{2}} \\
& =\frac{\left[2 K\left(a+b C_{m}\right)-A a b\right]\left(8 K b-B b^{2}\right)-\left[4 K\left(a+b C_{m}\right)-B a b\right]\left(4 K b-A b^{2}\right)}{\left(4 K b-A b^{2}\right)\left(8 K b-B b^{2}\right)}>0 .
\end{aligned}
$$

Proof (known condition). Consider the following:

(1) $0<X_{2}=\left(\Delta-H_{1}\right) /\left(2 H_{3}-2 H_{2}-H_{1}\right)<1$.

(2) According to the assumption (8), we can get the following:

$$
\begin{aligned}
A- & B=\left(\Delta-H_{1}\right)\left(H_{3}-2 H_{2}\right) X_{2}+\left(2 H_{2}-H_{1}\right)\left(H_{3}\right. \\
& \left.-2 H_{2}\right) X_{2}^{2}-\left[\left(\Delta-H_{1}\right)^{2}\right. \\
& +\left(\Delta-H_{1}\right)\left(H_{1}-2 H_{2}\right) X_{2}
\end{aligned}
$$

$$
\begin{aligned}
& \left.-\left(\Delta-H_{1}\right)\left(H_{1}-2 H_{2}\right) X_{2}^{2}-\left(H_{1}-2 H_{2}\right)\right] \\
& =\Delta H_{3} X_{2}+2 H_{2} H_{3} X_{2}^{2}+2 H_{2} H_{1} X_{2}^{2}+H_{1}^{2} X_{2} \\
& +\Delta H_{1} X_{2}^{2}+2 H_{2} H_{1} X_{2}^{2}+H_{1}-\left(\Delta-H_{1}\right)^{2} \\
& -\Delta H_{1} X_{2}-2 \Delta H_{2} X_{2}^{2}-H_{1}^{2} X_{2}^{2}-2 H_{2}-4 H_{2}^{2} X_{2}^{2} \\
& -H_{3} H_{1} X_{2}^{2}>0 .
\end{aligned}
$$

So $2 A>B$. 
(1) When $8 K b<B b^{2}, 8 K b<2 A b^{2}$ and numerator and denominator in (21) are multiplied by 2 , so we can get the following:

$$
P^{\circ}-P^{*}=\frac{4 K\left(a+b C_{m}\right)\left(8 K b-B b^{2}\right)-2 A a b\left(8 K b-B b^{2}\right)-4 K\left(a+b C_{m}\right)\left(8 K b-2 A b^{2}\right)+B a b\left(8 K b-2 A b^{2}\right)}{\left(8 K b-2 A b^{2}\right)\left(8 K b-B b^{2}\right)} .
$$

Because $\left(8 K b-2 A b^{2}\right)\left(8 K b-B b^{2}\right)>0$ and $B b^{2}<2 A b^{2}$, we can know that numerator is greater than 0 .

So $P^{\circ}-P^{*}>0$.
(2) When $B b^{2}<8 K b<2 A b^{2}$ and numerator and denominator in (21) are multiplied by 2 , then we can get the following:

$$
P^{\circ}-P^{*}=\frac{4 K\left(a+b C_{m}\right)\left(8 K b-B b^{2}\right)-2 A a b\left(8 K b-B b^{2}\right)-4 K\left(a+b C_{m}\right)\left(8 K b-2 A b^{2}\right)+B a b\left(8 K b-2 A b^{2}\right)}{\left(8 K b-2 A b^{2}\right)\left(8 K b-B b^{2}\right)}
$$

In this situation, $\left(8 K b-2 A b^{2}\right)\left(8 K b-B b^{2}\right)<0$; assume that $M=a+b C_{m}$; then the numerator is

$$
\begin{aligned}
W= & 32 K^{2} M b-4 K B M b^{2}-2 A a b\left(8 K b-B b^{2}\right) \\
& -32 K^{2} M b+8 K M A b^{2}+B a b\left(8 K b-2 A b^{2}\right) \\
& -4 K M B b^{2},
\end{aligned}
$$

and, after eliminating the same options, we can get that

$$
W=8 A K M b^{2}-4 A K M b^{2}+8 B K a b^{2}-2 A B a b^{2} .
$$

Because of the result from subtracting term one and term two is larger than 0 , the result from subtracting term three and term four is less than 0 , and

$$
2 A B a b^{2}-8 B K a b^{2}-8 A K M b^{2}+4 A K M b^{2}<0,
$$

and then the numerator is less than 0 too.

So $P^{\circ}-P^{*}>0$.

(3) When $B b^{2}<2 A b^{2}<8 K b$ and numerator and denominator in (21) are multiplied by 2 , then we can get the following:

$$
P^{\circ}-P^{*}=\frac{4 K\left(a+b C_{m}\right)\left(8 K b-B b^{2}\right)-2 A a b\left(8 K b-B b^{2}\right)-4 K\left(a+b C_{m}\right)\left(8 K b-2 A b^{2}\right)+B a b\left(8 K b-2 A b^{2}\right)}{\left(8 K b-2 A b^{2}\right)\left(8 K b-B b^{2}\right)}
$$

However, in this time, the denominator is larger than 0 ; this is different from $2^{\circ}$; the numerator is

$$
\begin{aligned}
W= & 32 K^{2} M b-4 K B M b^{2}-2 A a b\left(8 K b-B b^{2}\right) \\
& -32 K^{2} M b+8 K M A b^{2}+B a b\left(8 K b-2 A b^{2}\right) \\
& -4 K M B b^{2} \\
= & 8 A K M b^{2}-4 A K M b^{2}+8 B K a b^{2}-2 A B a b^{2},
\end{aligned}
$$

because of $B b^{2}<2 A b^{2}<8 K b, W>0$; then both of numerator and denominator are larger than 0 .

Above all, we can know that $P^{\circ}-P^{*}>0$.

The same goes for (10)-(17):

$$
\begin{aligned}
\gamma^{\circ}-\gamma^{*}= & \frac{X_{2}\left(H_{3}-2 H_{2}\right)\left(a-b C_{m}\right)}{4 K-A b} \\
& -\frac{\left[\left(\Delta-H_{1}\right)+\left(H_{1}-2 H_{2}\right)\right]\left(a+b C_{m}\right)}{8 K-B b}
\end{aligned}
$$

$$
>0 \text {. }
$$

Comparing (19) and (11) then use the transitivity of inequality. Since the sign of numerator and denominator are same, we can get that

$$
\begin{aligned}
& P^{\circ}>P^{*}, \\
& \gamma^{\circ}>\gamma^{*} .
\end{aligned}
$$

We use (15)-(19) to get the following:

$$
I^{*}>I^{\circ} \text {. }
$$

Analysis of the above conclusions is as follows:

(1) The price in independent supply chain model is larger than price in integrated supply chain model. This will increase the sales volume of underintegrated mode, which can continue to improve manufacturer's production level and efficiency, reduce production cost, and increase market demand. Thus, the profit of manufacturer and retailer will be enhanced as well as the whole supply chain. 
(2) The recovery has decreased under the integrated model, seems to reduced price of the integration of closed-loop supply chain, and raised the sales volume. As a result, product quality is also constantly improving, and the enterprise competition ability is increasingly reinforced.

(3) The profit of the supply chain under integrated model is greater than the profit under independent model, which means that integrated model is superior to independent model.

(4) The integrated model is good not only in profit, but also in product quality.

2.4. Revenue-Sharing Contract. In Stackelberg game, the integrated model is superior to independent model. However, how to get the optimum profit of the supply chain under game state? We need a coordination strategy (revenue-sharing contract). That is, profit is distributed reasonably between manufacturer and retailer. In this situation, we assume that manufacturer sell product to retailer with a price lower then cost and then assign the revenue between them. If the revenue proportion of retailer is $\theta$, manufacturer can get $1-\theta$.

So, the profit of manufacturer and retailer is

$$
\begin{aligned}
I_{M}= & (1-\theta) p(a-b p)+w(a-b p)-(a-b p) C_{m} \\
& -K \gamma^{2}-H_{1} X_{1} \gamma(a-b p)-H_{1} X_{1} \gamma(a-b p) \\
& -H_{3} X_{2} \gamma(a-b p)+\left(C_{m}-C_{r}\right) \gamma(a-b p), \\
I_{R}= & \theta p(a-b p)+\left(H_{3}-H_{2}\right) X_{2} b \gamma(a-b p) \\
& -w(a-b p)-K \gamma^{2}-H_{2} X_{2} b \gamma(a-b p) .
\end{aligned}
$$

Taking partial with respect to retailer profit formula can get the optimal price and recovery:

$$
\begin{aligned}
& \frac{\partial I_{R}}{\partial P}=\theta a-\theta b p-\left(H_{3}-H_{2}\right) X_{2} b \gamma+W b+H_{2} X_{2} b \gamma \\
& \frac{\partial I_{R}}{\partial \gamma}=\left(H_{3}-H_{2}\right) X_{2}(a-b p)-2 K \gamma-H_{2} X_{2} b \gamma \\
& P=\frac{\theta a+b\left(w-\left(H_{3}-H_{2}\right) X_{2} \gamma+\left(H_{3}-H_{2}\right) X_{2} \gamma\right)}{2 \theta b} \\
& \gamma=\frac{\left(H_{3}-2 H_{2}\right)(a-b p)}{2 K}
\end{aligned}
$$

This contract is based on the optimal profit of supply chain under the integrated model, so the obtained price and recovery in this case have to be equal to price and recovery under integrated mode. That is,

$$
\begin{aligned}
& P=P^{*}, \\
& \gamma=P^{*} .
\end{aligned}
$$

TABLE 1: The modeling parameters.

\begin{tabular}{lcccc}
\hline$a$ & $b$ & $C_{m}$ & $C_{r}$ & $K$ \\
\hline 1000 & 5 & 1000 & 50 & 4000 \\
\hline
\end{tabular}

Thus, the profit of manufacturer and retailer under revenuesharing contract is

$$
\begin{aligned}
& I_{R}=\theta\left(I^{*}+K \gamma^{* 2}\right)-K \gamma^{* 2}, \\
& I_{M}=(1-\theta)\left(I^{*}+K \gamma^{* 2}\right) .
\end{aligned}
$$

From revenue-sharing contract, we can get conclusions as follows:

(1) By taking revenue-sharing contract, we can see that the whole supply chain can cooperate more closely and coordinate more orderly. The efficiency of the supply chain can reach the maximum.

(2) The manufacturer and distributor are independent in reality, so we only need to cooperate better to make the maximum profit when we make decisions. It also reflects the necessity of node enterprise cooperation in supply chain.

(3) In this contract, profit allocation seems more reasonable, the supply chain can be more harmonious, and it also has an important significance to sustainable development of enterprises.

\section{Numerical Example}

Numerical example analysis is to verify dual-channel recycling and revenue sharing model under the related assumptions in this paper. The different conditions often lead to different results. The selected numerical value should be set up under the related premises. For example, assuming that there is only one manufacturer and one supplier, the value of $a$ and $b$ in the market demand function is $a=1000, b=5$; the value of $K$ is 4000 in the cost function of the glass packaging products retailer and manufacturer; the unit cost of recycling and reuse is $C_{m}=1000 \mathrm{RMB} /$ piece; the unit cost of using raw materials to make the new glass packaging products is $C_{r}=50 \mathrm{RMB} /$ piece; and the value of $H$ is $H_{1}=30, H_{2}=12$, and $H_{3}=40$; see Table 1 .

Put them in profit formula:

(1) Under the model of independent supply chain,

the optimal price and the recovery rate is $P^{\circ}=$ $154.41, \gamma^{\circ}=0.42$;

the profits of the manufacturer and distributor are $I_{R}^{\circ}=5522.93, I_{M}^{\circ}=11511.22$;

the profit of the whole supply chain is $I_{M}^{\circ}+I_{R}^{\circ}=$ $5522.93+11511.22=17034.15$.

(2) Under the integrated supply chain model,

the optimal price and the recovery rate is $P^{*}=$ $146.08, \gamma^{*}=0.41$;

the profits of the whole supply chain are $I^{*}=$ 24371.83. 
Because of $I^{*}>I^{\circ}$, we can see that the supply chain profit in a whole decision-making will be greater than in a separate decision-making. After adding the income distribution proportion coefficient into the integrated model, we can get

$$
P=146.08 \gamma=0.41 \text {. }
$$

The profits of the distributors and manufacturers are

$$
\begin{aligned}
& I_{M}^{*}=(1-\theta)(24371.82+673.24), \\
& I_{R}^{*}=\theta(24371.82+673.24)-673.24,
\end{aligned}
$$

$$
0.03 \leq \theta \leq 0.51
$$

It can be seen that the value of $\theta$ infected the distribution of profits between the distributors and manufacturers. With the increase of $\theta$, the manufacturers' profits will decrease and the distributors' profits will increase. Since this is the optimal supply chain profits under the integrated model, sellers can achieve a win-win situation and only set a proportion of profits allocation between the manufacturers and distributors. If the allocation proportion is unreasonable, of course, this will destroy the cooperation relations for the profits of one side being too low. This is unworkable. We can see that this regulatory mechanism is very flexible.

There are the following conclusions from the above analysis.

(1) The revenue-sharing contract is distributed and determines that the supply chain profit of integrated mode is higher than that of individual decision. That means that the profit of the whole supply chain stays the same. In this situation, making full use of distribution coefficient can adjust the profits between the manufacturers and retailers, improve the efficiency of the system, and thus make the revenuesharing contract become a great coordinate tool.

(2) The conclusion of the integrated decision is better than the individual decision that just applies to the background of the Stackelberg balanced decisions. Therefore the revenuesharing contract also seems to be reasonable and flexible under this precondition. Of course, theoretically, the law of decreasing marginal benefit makes integration decisionmaking superior to individual decision. But this is the general rule. In the daily life, since the differences of enterprise system and strategy often appear in many special premises, so it is not all the industries applicable in such decision mode.

\section{Conclusions}

It is not a long time that the logistics development in China since introduced from abroad, but the economic development facilitates the development of it. To prompt more people dedicated to research in this area, through above analysis, we can find that (1) due to the differences in cost, price, and recovery rate, the conclusions will be different. In other words, not every kind of waste products is worth to be recovered for the enterprise, only through accurate statistics and calculation the value can be found; (2) cooperation can promote the maximization of profit; independent operation often leads to the lack of information so that irrational allocation of resources is made. However, there are still some limitations in this paper. For example, the model does not refine the constraints, so the application of the model should be optimize when using it; this study has a great relationship with the specific conditions in developing country; it is not a general analysis method.

\section{Competing Interests}

The authors declare that there are no competing interests regarding the publication of this paper.

\section{Acknowledgments}

This research was supported by the National Natural Science Foundation Council of China under Project no. 71502159; the Applied Basic Research Science Foundation of Yunnan Provincial Department of Science and Technology under Project no. 2015FD028; the Science Foundation of Yunnan Provincial Department of Education under Project no. 2015Y269; The Science and Technology Innovation Team Fund of Logistics Engineering in Colleges and Universities of Yunnan Province in China.

\section{References}

[1] L. V. Jun, "The new development of closed loop supply chain research: from the perspective of business value," Journal of Business Economics, vol. 1, pp. 13-18, 2011.

[2] Y. M. Pan, X. L. Shan, Y. X. Duan, and S. O. Management, "Cost-benefit optimization analysis of reverse logistics," Value Engineering, vol. 14, pp. 12-13, 2015.

[3] K. Govindan, H. Soleimani, and D. Kannan, "Reverse logistics and closed-loop supply chain: a comprehensive review to explore the future," European Journal of Operational Research, vol. 240, no. 3, pp. 603-626, 2015.

[4] L. Lu, X. Qi, and Z. Liu, "On the cooperation of recycling operations," European Journal of Operational Research, vol. 233, no. 2, pp. 349-358, 2014.

[5] H. Zerhouni, J.-P. Gayon, and Y. Frein, "Influence of dependency between demands and returns in a reverse logistics system," International Journal of Production Economics, vol. 143, no. 1, pp. 62-71, 2013.

[6] P. D. Giovanni and G. Zaccour, "A two-period game of a closedloop supply chain," European Journal of Operational Research, vol. 232, no. 1, pp. 22-40, 2014.

[7] J. Wei and H. Wei, "A study on the reclaim cooperation with the third-party reverse logistics enterprises," Journal of Systems \& Management, vol. 6, pp. 702-709, 2011.

[8] I.-H. Hong and J.-S. Yeh, "Modeling closed-loop supply chains in the electronics industry: a retailer collection application," Transportation Research Part E: Logistics \& Transportation Review, vol. 48, no. 4, pp. 817-829, 2012.

[9] X. Zhou, "Allocation mechanism in inbound logistics based on multi-principal and multi-agent model," Journal of Management Sciences in China, vol. 10, pp. 77-84, 2011.

[10] C.-H. Chuang, C. X. Wang, and Y. Zhao, "Closed-loop supply chain models for a high-tech product under alternative reverse channel and collection cost structures," International Journal of Production Economics, vol. 156, pp. 108-123, 2014. 
[11] T. R. P. Ramos, M. I. Gomes, and A. P. Barbosa-Póvoa, "Planning a sustainable reverse logistics system: balancing costs with environmental and social concerns," Omega, vol. 48, pp. 60-74, 2014.

[12] Y. Y. Wang, "The closed-loop supply chain models analysis based on dual channel taking-back under government intervention," Operations Research Management Science, vol. 21, pp. 250255, 2012.

[13] M. Huang, M. Song, L. H. Lee, and W. K. Ching, "Analysis for strategy of closed-loop supply chain with dual recycling channel," International Journal of Production Economics, vol. 144, no. 2, pp. 510-520, 2013.

[14] Y. He, "Acquisition pricing and remanufacturing decisions in a closed-loop supply chain," International Journal of Production Economics, vol. 163, pp. 48-60, 2015.

[15] X. Hao, "Coordination research on closed-loop supply chain with dual-channel sale and dual-channel recovery," Statistics \& Information Tribune, vol. 6, pp. 87-92, 2015.

[16] C. Ma, "Research progress of closed-loop supply chain based on recycling remanufacturing," Knowledge Economy, vol. 4, pp. 104-106, 2015.

[17] J. Wei and J. Zhao, "Pricing decisions with retail competition in a fuzzy closed-loop supply chain," Expert Systems with Applications, vol. 38, no. 9, pp. 11209-11216, 2011.

[18] Y. Liang, S. Pokharel, and G. H. Lim, "Pricing used products for remanufacturing," European Journal of Operational Research, vol. 193, no. 2, pp. 390-395, 2009.

[19] Y.-Y. Yi and J.-M. Liang, "Hybrid recycling modes for closedloop supply chain under premium and penalty mechanism," Computer Integrated Manufacturing Systems, vol. 20, no. 1, pp. 215-223, 2014.

[20] C.-T. Zhang and S.-L. Yang, "Pricing and coordination strategy of closed-loop supply chain under dual channel recovery," Computer Integrated Manufacturing Systems, vol. 19, no. 7, pp. 1676-1683, 2013. 


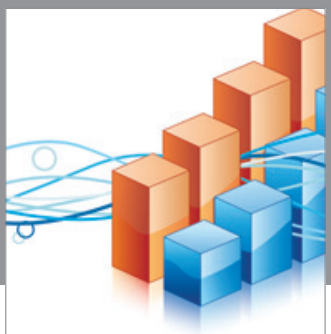

Advances in

Operations Research

vatem alat4

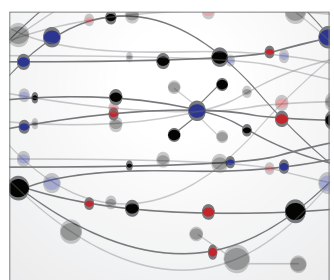

\section{The Scientific} World Journal
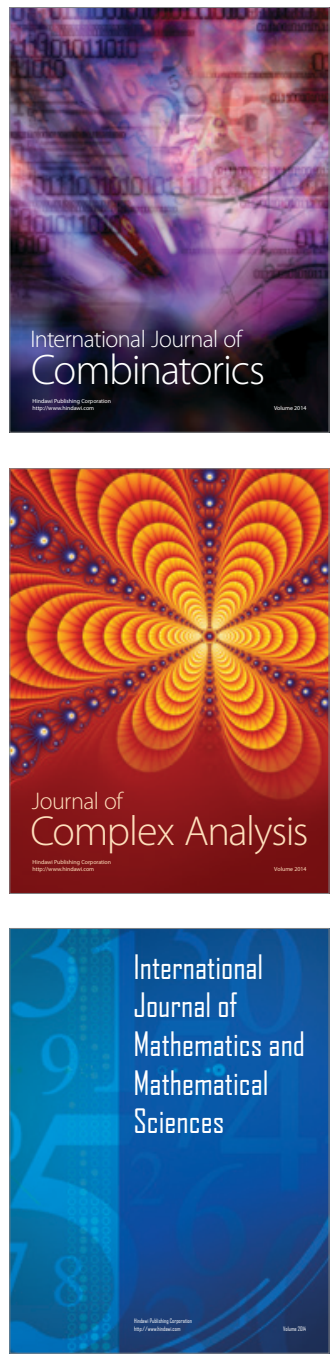
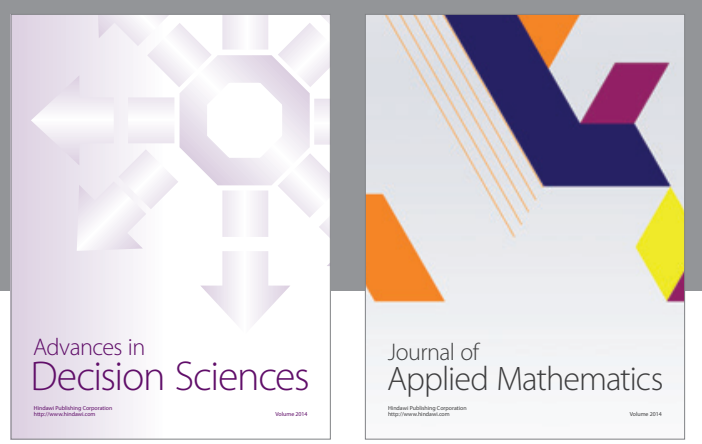

Algebra

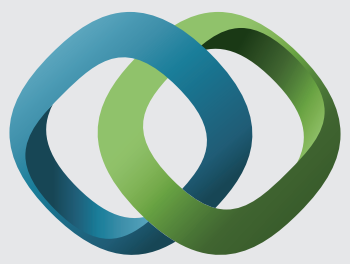

\section{Hindawi}

Submit your manuscripts at

http://www.hindawi.com
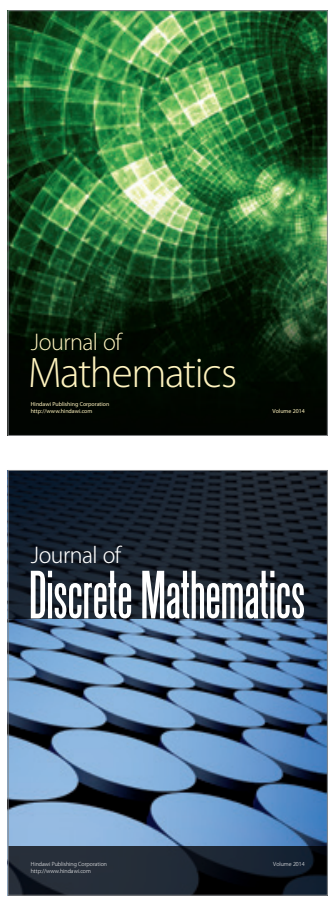

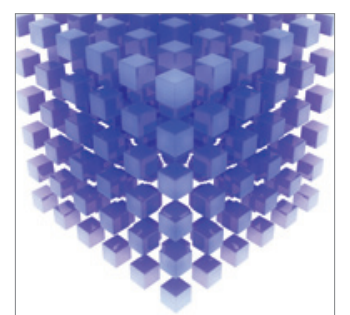

Mathematical Problems in Engineering
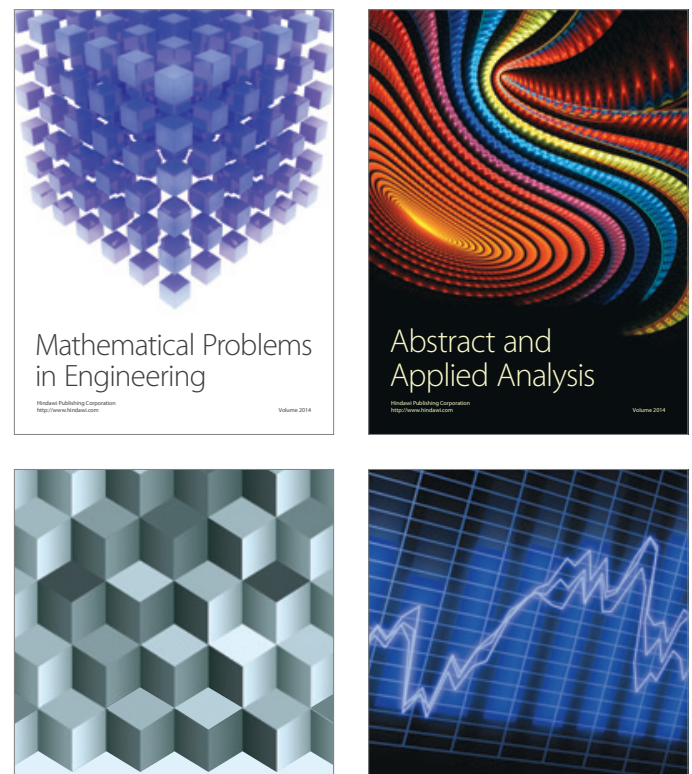

Journal of

Function Spaces

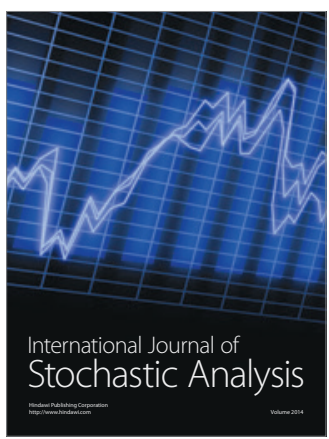


